Article

\title{
Optimization of Diverse Carbon Sources and Cultivation Conditions for Enhanced Growth and Lipid and Medium-Chain Fatty Acid (MCFA) Production by Mucor circinelloides
}

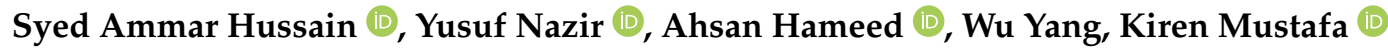 \\ and Yuanda Song * \\ Colin Ratledge Center for Microbial Lipids, School of Agriculture Engineering and Food Science, \\ Shandong University of Technology, Zibo 255049, China; ammarshah88@yahoo.com (S.A.H.); \\ yusufnazir91@yahoo.com (Y.N.); ahsanhameed@outlook.com (A.H.); neverhangsome@hotmail.com (W.Y.); \\ mustafakiran92@gmail.com (K.M.) \\ * Correspondence: ysong@sdut.edu.cn; Tel.: + 86-139-0617-4047
}

Received: 27 March 2019; Accepted: 18 April 2019; Published: 23 April 2019

check for updates

\begin{abstract}
The effects of various carbon sources and cultivation conditions on the growth kinetics, lipid accumulation, and medium-chain fatty acid (MCFA) production of Mucor circinelloides (MC) was investigated for $72 \mathrm{~h}$ in shake flask cultivation. Our previous investigation reported increments of 28 to $46 \%$ MCFAs among total cell lipids when the MC genome was genetically modified, in comparison to the wild-type. However, the growth of the engineered strain M65-TE-04 was adversely affected. Therefore, the current study was designed to enhance the growth, lipid production, and MCFA productivity of engineered $M$. circinelloides by optimizing the $\mathrm{pH}$, agitation speed, temperature, and carbon sources. The findings for individual variables disclosed that the highest biomass $(17.0 \mathrm{~g} / \mathrm{L})$ was obtained when coconut oil mixed with glucose was used as a carbon source under normal culture conditions. Additionally, the maximum lipid contents (67.5\% cell dry weight (CDW)), MCFA contents $(53 \%$ total fatty acid (TFA)), and overall lipid productivity $(3.53 \mathrm{~g} / \mathrm{L} \cdot \mathrm{d})$ were attained at $26^{\circ} \mathrm{C}, \mathrm{pH}$ 6.0, and $150 \mathrm{rpm}$, respectively. The maximum biomass (19.4 g/L), TFA (14.3g/L), and MCFA $(4.71 \mathrm{~g} / \mathrm{L})$ contents were achieved with integration of a temperature of $26^{\circ} \mathrm{C}, \mathrm{pH}$ 6.0, agitation speed $300 \mathrm{rpm}$, and coconut oil mixed medium as the carbon source. This work illustrates that biomass, TFA, and MCFA contents were increased 1.70-2.0-fold by optimizing the initial $\mathrm{pH}$, agitation speed, temperature, and carbon sources in the M. circinelloides engineered strain (M65-TE-04) in comparison to initial cultivation conditions.
\end{abstract}

Keywords: Mucor circinelloides; microbial lipids; medium-chain fatty acids; culture optimization

\section{Introduction}

Currently, single cell oil (SCO) is considered as an alternative and reliable platform to face the challenges related to global warming, scarcity of non-renewable resources, and food security. Over the last decade, medium-chain fatty acids (MCFAs: C8 to C12) and their derivatives have been gaining attention because of their diverse applications in the food, biochemical, and petroleum industries [1]. These MCFAs are involved as precursors in industries involved in the manufacturing of bio-plasticizers, lubricants, detergents, surfactants, adhesives, antibiotics, diverse intermediates for floral fragrances, and flavors [2]. The aforementioned fatty acids have attracted much attraction because they have a positive impact on human health by being easily absorbed and swiftly catabolized through the $\beta$-oxidation mechanism, ultimately increasing diet-stimulated thermo-genesis [3]. This mechanism 
provides a venue for the prevention of various metabolic abnormalities, such as obesity, hyperlipidemia, type II diabetes, atherosclerosis, and cardiovascular diseases (CVDs). The yield of naturally produced MCFAs from plant (i.e., coconut or palm) sources has been estimated to be insignificant to meet the market demand [2-12]. Therefore, diverse metabolic-engineering strategies have been exploited in different oleaginous microorganisms to augment the contents of MCFAs [13-22]. In addition, numerous investigations have been performed to evaluate the effects of carbon and nitrogen sources, initial $\mathrm{pH}$ of the culture medium, $\mathrm{C} / \mathrm{N}$ ratio, incubation temperature, and their particular effects on the fungal biomass and fatty acid production [23-32]. However, comprehensive information regarding MCFA production under diverse culture conditions is still limited.

Mucor circinelloides is regarded as a model organism for investigations of lipid accumulation. It has been extensively genetically manipulated for the production of diverse biotechnological precursors for the functional food and bio-fuel industries [1,33,34]. However, its fatty acid profile indicates that it is mostly formed by long-chain fatty acids (LCFAs), ultimately making it less attractive for multi-purpose industrial applications. In our previous investigation, efforts to enhance the MCFA content were carried out by integrating different heterologous thioesterase (TE) proteins from plant and bacterial sources into the fatty acid synthase (FAS) complex of the M. circinelloides M65 strain, eventually generating mutant strains with significant MCFA-producing capability [1]. Although we successfully enhanced the MCFA contents from the total fatty acids (TFAs), a noteworthy decline in biomass in the resultant strains was observed, which negatively affected the lipid productivity and MCFA contents. Thus, to circumvent the productivity-related challenge stemming from the dry cell weight (CDW) of the M. circinelloides strain, M65-TE-04, we synergistically optimized the culture conditions to maximize the yield of MCFAs. The individual and synergistic impact of four key factors, namely the incubation temperature, initial $\mathrm{pH}$, agitation speed, and different carbon sources, were evaluated, and the impact on the biomass and lipid and MCFA contents of $M$. circinelloides strains was elucidated.

\section{Material and Methods}

\subsection{Microorganisms, Culture Conditions, and Experimental Design}

The genetically manipulated strain of $M$. circinelloides M65 (i.e., a uracil auxotroph of $M$. circinelloides WJ11), M65-TE-04 (i.e., acyl-ACP-thioesterases: TE-over-expressing strain) from our recent investigation [1], was employed in the present study. This engineered strain was initially inoculated by applying $100 \mu \mathrm{L}$ of spore suspension ( $10^{7}$ spores/mL) into $150 \mathrm{~mL}$ of Kendrick and Ratledge (K and R) medium (i.e., $30 \mathrm{~g} / \mathrm{L}$ glucose, $3.3 \mathrm{~g} / \mathrm{L}$ ammonium tartrate, $7.0 \mathrm{~g} / \mathrm{L} \mathrm{KH}_{2} \mathrm{PO}_{4}, 2.0 \mathrm{~g} / \mathrm{L} \mathrm{Na}_{2} \mathrm{HPO}_{4}, 1.5 \mathrm{~g} / \mathrm{L} \mathrm{MgSO} \cdot 7 \mathrm{H}_{2} \mathrm{O}, 1.5 \mathrm{~g} / \mathrm{L}$ yeast extract, $0.1 \mathrm{~g} / \mathrm{L} \mathrm{CaCl} 2 \cdot 2 \mathrm{H}_{2} \mathrm{O}, 8 \mathrm{mg} / \mathrm{L} \mathrm{FeCl}_{3} \cdot 6 \mathrm{H}_{2} \mathrm{O}, 1 \mathrm{mg} / \mathrm{L} \mathrm{ZnSO} \cdot 7 \mathrm{H}_{2} \mathrm{O}, 0.1 \mathrm{mg} / \mathrm{L} \mathrm{CuSO}_{4} \cdot 5 \mathrm{H}_{2} \mathrm{O}, 0.1 \mathrm{mg} / \mathrm{L}$ $\mathrm{Co}\left(\mathrm{NO}_{3}\right)_{2} \cdot 6 \mathrm{H}_{2} \mathrm{O}$, and $0.1 \mathrm{mg} / \mathrm{L} \mathrm{MnSO}_{4} \cdot 5 \mathrm{H}_{2} \mathrm{O}$ [1] held in a $1 \mathrm{~L}$ baffled shake flask. Culture were incubated at $30{ }^{\circ} \mathrm{C}$ for $24 \mathrm{~h}$ with shaking at $150 \mathrm{rpm}$ and employed at $10 \%(v / v)$ to inoculate $1 \mathrm{~L}$ baffled shake flask containing $150 \mathrm{~mL}$ modified $\mathrm{K}$ and $\mathrm{R}$ medium (i.e., glucose (80 g/L), coconut oil (30 g/L) with glucose $(50 \mathrm{~g} / \mathrm{L})$, palm oil (30 g/L) with glucose $(50 \mathrm{~g} / \mathrm{L})$, glycerol $30 \mathrm{~g} / \mathrm{L})$ with glucose $(50 \mathrm{~g} / \mathrm{L})$, plus essential salts, as mentioned above). To evaluate the effects of the different culture conditions on the growth kinetics and MCFA production, the initial $\mathrm{pH}$, agitation speed, incubation temperature, and different carbon sources were examined using the engineered $M$. circinelloides strain (M65-TE-04). To achieve our aim, a range of pH values (i.e., 4.5, 6.0, 7.5), agitation speeds (i.e., $150 \mathrm{rpm}, 220 \mathrm{rpm}, 300 \mathrm{rpm}$ ), temperatures (i.e., $26^{\circ} \mathrm{C}$, $\left.30{ }^{\circ} \mathrm{C}, 34^{\circ} \mathrm{C}\right)$, and different carbon sources (i.e., glucose $(80 \mathrm{~g} / \mathrm{L})$, coconut oil $(30 \mathrm{~g} / \mathrm{L})$ with glucose $(50 \mathrm{~g} / \mathrm{L})$, palm oil $(30 \mathrm{~g} / \mathrm{L})$ with glucose $(50 \mathrm{~g} / \mathrm{L})$, glycerol $30 \mathrm{~g} / \mathrm{L})$ with glucose $(50 \mathrm{~g} / \mathrm{L}))$ were tested for $72 \mathrm{~h}$ in the current investigation. All the materials were autoclaved at $121{ }^{\circ} \mathrm{C}$ for $20 \mathrm{~min}$. All the above-described chemicals were procured from Millipore Sigma (St. Louis, MO, USA), and all experiments were performed three times for reproducibility purposes. 


\subsection{Determination of Cell Dry Weight (CDW)}

Harvesting of the fungal biomass was carried out according to our previously described method [1]. In brief, a suction filtration method was employed followed by three washes with double-distilled water to eliminate possible medium contents. The collected samples were then frozen at $-80{ }^{\circ} \mathrm{C}$ overnight, and the samples were lyophilized for $24 \mathrm{~h}$. The fungal biomass weight was calculated by the gravimetrical method.

The biomass productivity $\left(P_{D C W}\right)$ of fungal cells was computed using the following equation:

$$
P_{D C W}(\mathrm{~g} / \mathrm{L} \cdot \mathrm{d})=\left(C D W_{f}-C D W_{i}\right) /\left(T_{f}-T_{i}\right)
$$

\subsection{Total Lipid and Fatty Acid Profiling}

Lipid extraction was performed according to a previously developed method with minor modifications [1]. In brief, $20 \mathrm{mg}$ of lyophilized biomass was mixed with chloroform/methanol $(2: 1, v / v)$. Methylation was carried out with $10 \%(v / v)$ methanolic $\mathrm{HCl}$ at $60^{\circ} \mathrm{C}$ for $4 \mathrm{~h}$. Pentadecanoic acid (15:0) (Millipore Sigma, St. Louis, MO, USA) was used as an internal standard for the lyophilized cells before methylation. Finally, the fatty acid methyl esters (FAMEs) were extracted with n-hexane and subsequently analyzed by GC using the DB-Waxetr column with the following specifications: film thickness $0.25 \mu \mathrm{m}, 30 \mathrm{~m} \times 0.32 \mathrm{~mm}$ (Shimadzu Co., Ltd., Kyoto, Japan). The program used for the gas chromatography (GC) was as follows: $120^{\circ} \mathrm{C}$ for $3 \mathrm{~min}$, ramp to $200^{\circ} \mathrm{C}$ at $5^{\circ} \mathrm{C} \mathrm{min}^{-1}$, ramp to $220^{\circ} \mathrm{C}$ at $4{ }^{\circ} \mathrm{C} \min ^{-1}$, and hold for $2 \min [1,33]$.

Lipid productivity $\left(P_{\text {Lipid }}\right)$ and MCFA productivity $\left(P_{M C F A}\right)$ were calculated as follows:

$$
\begin{gathered}
P_{\text {Lipid }}(\mathrm{g} / \mathrm{L} \cdot \mathrm{d})=\left(\operatorname{Lipid}_{f}-\operatorname{Lipid}_{i}\right) /\left(T_{f}-T_{i}\right) \\
P_{M C F A}(\mathrm{~g} / \mathrm{L} \cdot \mathrm{d})=\left(M C F A_{f}-M C F A_{i}\right) /\left(T_{f}-T_{i}\right)
\end{gathered}
$$

where $C_{\mathrm{f}}$ is the final lipid content $(\mathrm{g} / \mathrm{L}), \mathrm{C}_{\mathrm{i}}$ is initial lipid content, and TL is the total lipid content.

\subsection{Construction of Orthogonal Matrix Design (OMD)}

The synergistic effect of all parameters was evaluated on the bases of OMD design, as shown in Table 1.

Table 1. Orthogonal matrix design (OMD) to evaluate the diverse culture conditions (coded values for factors and their levels).

\begin{tabular}{ccccc}
\hline Factors & Code $\mathbf{1}$ & Code 2 & Code 3 & Code 4 \\
\hline Temperature & $24{ }^{\circ} \mathrm{C}$ & $26{ }^{\circ} \mathrm{C}$ & $30{ }^{\circ} \mathrm{C}$ & $34{ }^{\circ} \mathrm{C}$ \\
Agitation & $150 \mathrm{rpm}$ & $220 \mathrm{rpm}$ & $300 \mathrm{rpm}$ & - \\
pH & 4.5 & 6 & 7.5 & - \\
Carbon Source & Glucose & Palm-oil + glucose & Coconut-oil + glucose & Glycerol + glucose \\
\hline
\end{tabular}

\subsection{Statistical Analysis}

A statistical analysis of the acquired data was performed with SPSS 16.0 for Windows (SPSS Inc., Chicago, IL, USA). Mean values and the standard error of the mean were computed from the data gathered from three independent experiments. The Student's t-test was employed to estimate differences between the data, and $p<0.05$ was regarded as a significant difference.

\section{Results and Discussion}

To investigate the effect of diverse cultivation conditions of the $M$. circinelloides strain (i.e., M65-TE-04) on cell growth, lipid accumulation, and MCFA production, four key cultivation factors (i.e., incubation temperature, initial $\mathrm{pH}$, speed of agitation, and carbon-sources) were assessed in a first 
stage individually, and in a second stage in a combinatorial study following orthogonal matrix design (OMD). When individual culture conditions were evaluated, all the remaining culture factors were held constant. These conditions were analogous to the normal culture conditions to eventually attain particular conclusions on the basis of relevant variable effects on cell growth and lipid accumulation.

\subsection{Effect of Incubation Temperature on Fungal Biomass and Lipid Accumulation}

Fungal biomass, lipid accumulation, and MCFA contents of M. circinelloides strain M65-TE-04 cultured on modified $\mathrm{K}$ and $\mathrm{R}$ medium were appraised at three different temperatures (i.e., $26{ }^{\circ} \mathrm{C}$, $30{ }^{\circ} \mathrm{C}$, and $34{ }^{\circ} \mathrm{C}$ ) for $72 \mathrm{~h}$. After 3 days of cultivation, the biomass (CDW, g/L) acquired at the different temperatures is shown in Figure 1A. Overall, we noticed a fluctuation of fungal growth at different cultivation temperatures. The biomass at $26{ }^{\circ} \mathrm{C}$ was considerably higher (i.e., $13 \mathrm{~g} / \mathrm{L}$ ) than at other temperatures. The quantity of biomass gradually declined with an increase in temperature (i.e., $9.5 \mathrm{~g} / \mathrm{L}$ and $4.6 \mathrm{~g} / \mathrm{L}$ for $30^{\circ} \mathrm{C}$ and $34{ }^{\circ} \mathrm{C}$, respectively) (Figure $1 \mathrm{~A}$ ). This pattern clearly demonstrated that higher temperature was not appropriate for fungal cell growth.

Temperature is regarded as a crucial factor for fungal cell growth, overall lipid productivity, and specifically MCFA contents. We noticed an inverse correlation between the cultivation temperature and MCFA contents. High MCFA contents were found at $26^{\circ} \mathrm{C}$ (i.e., 50\%), which were approximately 1.3-fold higher than the titer obtained at $34^{\circ} \mathrm{C}$ (Figure 1A). Likewise, the lipid contents (\% CDW) also declined with the temperature elevation (Figure 1B). The maximum lipid accumulation was obtained at $26{ }^{\circ} \mathrm{C}$, which was almost $63 \%$ higher than that at $34{ }^{\circ} \mathrm{C}$. Finally, we noticed a considerable fluctuation in biomass and lipid productivity $(p>0.05)$, as shown in Figure $1 \mathrm{C}$. These outcomes indicated that the optimal temperature for fungal cell growth, as well as for lipid and MCFA productivity, was $26^{\circ} \mathrm{C}$. The maximum biomass (i.e., $4.37 \mathrm{~g} / \mathrm{L} \cdot \mathrm{d}$ ) and lipid productivity (i.e., $2.93 \mathrm{~g} / \mathrm{L} \cdot \mathrm{d}$ ) were achieved at $26^{\circ} \mathrm{C}$. Our results are in agreement with a previous investigation conducted using $M$. circinelloides strains, which demonstrated maximum cell growth and lipid production at temperatures ranging from $26^{\circ} \mathrm{C}$ to $30^{\circ} \mathrm{C}[34,35]$. Moreover, the optimum temperature for growth and lipid accumulation in other fungal strain has been estimated to range from $26^{\circ} \mathrm{C}$ to $30^{\circ} \mathrm{C}$ [36].

\subsection{Effect of the Initial $p H$ of the Culture Medium on Fungal Biomass and Lipid Accumulation}

In the current investigation, the M. circinelloides strain (i.e., M65-TE-04) was able to grow at different $\mathrm{pH}$ values (i.e., 4.5, 6.0, and 7.5) (Figure 2A). Overall, $\mathrm{pH}$ values below or above 6.0 had drastic effects on the growth of $M$. circinelloides strains, as growth declined after $24 \mathrm{~h}$ of the cultivation period. Although $M$. circinelloides strains could grow within a wide $\mathrm{pH}$ range, the maximum growth was observed at $\mathrm{pH}$ 6.0. The highest biomass content (CDW; $12.5 \pm 2.1 \mathrm{~g} / \mathrm{L}$ ) was achieved in culture at an initial $\mathrm{pH}$ of 6.0 over culture duration of $72 \mathrm{~h}$. The biomass of $M$. circinelloides strains at different $\mathrm{pH}$ values is elaborated in Figure 2A. Our findings are in agreement with our previous studies [1]. However, some authors have reported that the fungal growth rate was found to be maximal at $\mathrm{pH} 4.5$ [37].

The $\mathrm{pH}$ value is a crucial cultivation factor that affects cell surface characteristics, ultimately modifying the cellular permeability capacity for different ions, bases, and acids across the membrane. It also has a great influence on the cellular metabolism of carbohydrates, proteins, and lipids. Moreover, the depletion of nutrients, i.e., phosphorus, nitrogen, or sulfur, also affects biochemical processes in the microorganism. Thus, in the current investigation, we provided an altered nutrient supply to fungal strain by using the different initial pHs of culture mediums (i.e., 4.5, 6.0, and 7.5). As depicted in Figure 2B, we observed that increasing the $\mathrm{pH}$ (4.5 to 6.0) had a positive effect on the TFA content (\% CDW). More precisely, the maximum lipid contents were obtained at pH 6.0 (i.e., 64.3\% of CDW). Similarly, the MCFA contents were slightly influenced by the initial culture $\mathrm{pH}$, and maximum MCFA contents (\% CDW) were attained at pH 6.0 (Figure 2A). However, no obvious alterations in other saturated fatty acids were observed for all culture initial $\mathrm{pH}$ values. There were no significant changes in lipid and MCFA contents at pH 4.5 and 7.5 (Figure 2A,B). 

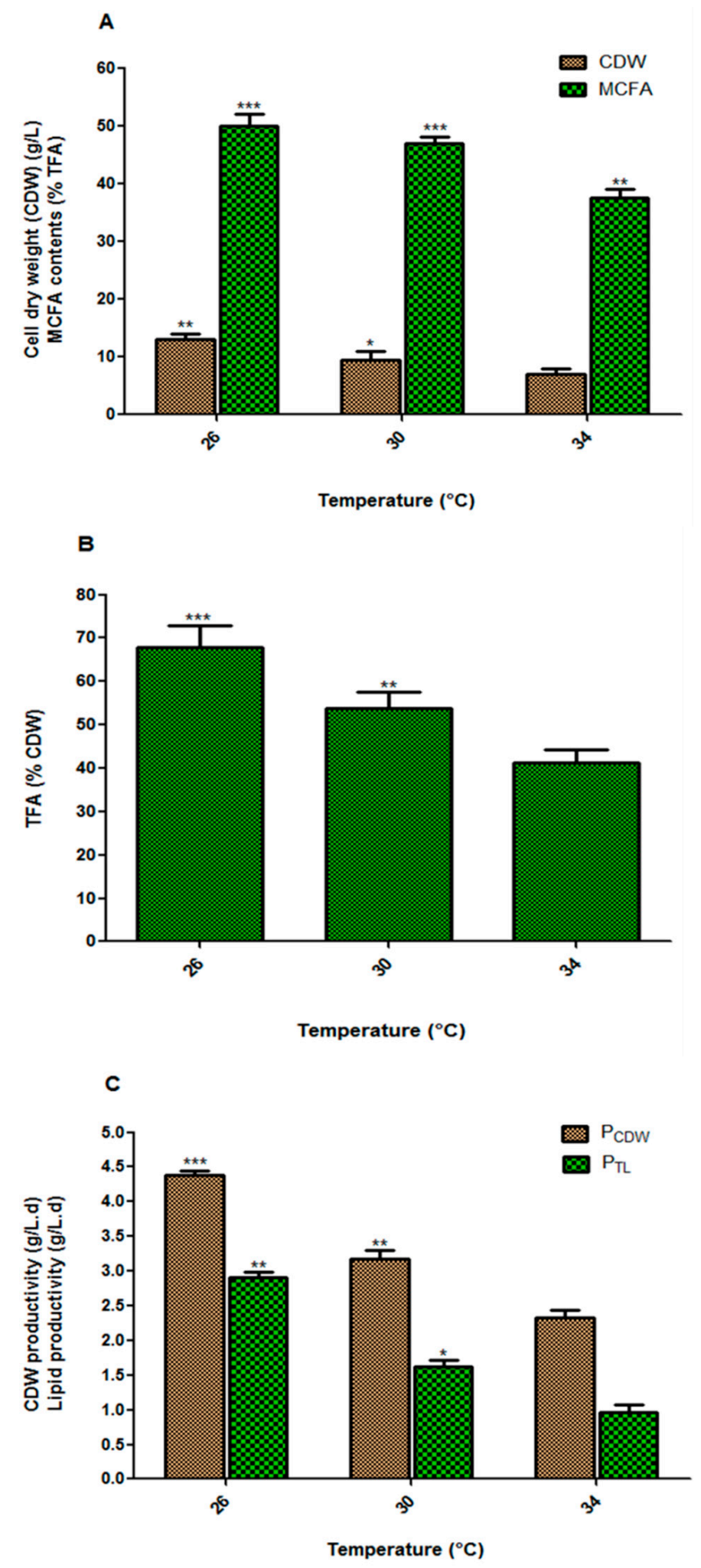

Figure 1. (A-C) Effect of temperature on (A) cell dry weight (CDW, g/L) and MCFA content (\% TLC), (B) fungal TFA $(\% \mathrm{CDW}),(\mathrm{C})$ biomass productivity $\left(\mathrm{P}_{\mathrm{CDW}}, \mathrm{g} / \mathrm{L} \cdot \mathrm{d}\right)$, and lipid productivity $\left(\mathrm{P}_{\mathrm{TL}}, \mathrm{g} / \mathrm{L} \cdot \mathrm{d}\right)$ of the M. circinelloides strain (i.e., M65-TE-04) after $72 \mathrm{~h}$ (3 days) of cultivation. Values are the mean of three independent experiments. Error bars show the standard error of the mean. Asterisks indicate that the differences $\left({ }^{*} p<0.05 ;{ }^{* *} p<0.01 ;{ }^{* * *} p<0.001\right)$ between the means of different treatments are statistically significant. 

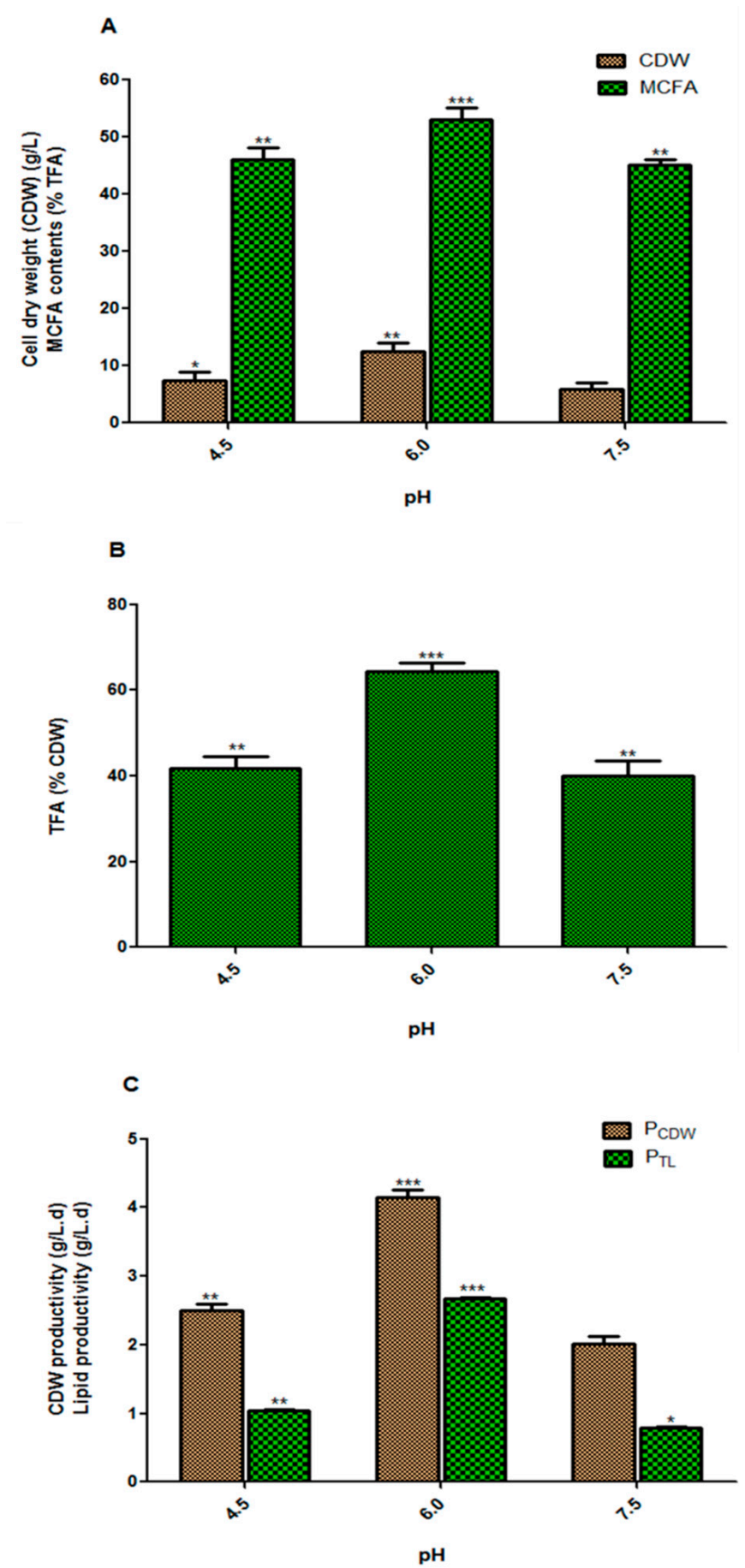

Figure 2. (A-C) Effect of initial pH on (A) cell dry weight (CDW, g/L) and MCFA content (\% TLC), (B) fungal TFA (\% CDW), (C) biomass productivity $\left(\mathrm{P}_{\mathrm{CDW}}, \mathrm{g} / \mathrm{L} \cdot \mathrm{d}\right)$, and lipid productivity $\left(\mathrm{P}_{\mathrm{TL}}, \mathrm{g} / \mathrm{L} \cdot \mathrm{d}\right)$ of the M. circinelloides strain (i.e., M65-TE-04) after $72 \mathrm{~h}$ (3 days) of cultivation. Values are the mean of three independent experiments. Error bars show the standard error of the mean. Asterisks indicate that the differences $\left({ }^{*} p<0.05 ;{ }^{* *} p<0.01 ;{ }^{* * *} p<0.001\right)$ between the means of different treatments are statistically significant.

The association of cell dry weight $(\mathrm{CDW})$ and lipid productivities $(\mathrm{g} / \mathrm{L})$ provided noteworthy insight into cell growth at different initial $\mathrm{pH}$ values of the culture medium. The biomass and lipid productivities are mentioned in Figure 2C. The maximum biomass and lipid productivity were achieved at $\mathrm{pH}$ 6.0, whereas the minimum productivities for the biomass and lipid contents were found at 
$\mathrm{pH} 7.5$ (Figure 2C). A previous report has shown that the $\mathrm{pH}$ values of fungal cells are sustained by ion exchange systems across the cell membranes, which eventually fabricate the electric potential with an intracellular positive charge at the cost of cellular energy. At a $\mathrm{pH}$ value other than the optimal level for fungal biomass growth, more energy is required to properly maintain the physiological tasks. Therefore, biomass and lipid productivities are maximal at $\mathrm{pH} 6.0[33,34,38]$.

\subsection{Effect of Agitation Speed on Fungal Biomass and Lipid Accumulation}

When all the culture parameters (i.e., substrate, temperature, initial $\mathrm{pH}$, etc.) of the culture medium were optimized, the specific growth rate was solely associated with the accessibility of dissolved oxygen (DO). To improve the DO, we cultured fungal strain M64-TE-04 at diverse agitation speeds (i.e., 150, 220, and $300 \mathrm{rpm}$ ). The fungal biomass, lipid accumulation, and MCFA contents and their productivities are demonstrated in Figure 3A-C. We observed a significant change in biomass and MCFA contents with a corresponding increase in agitation speed from 150 to $220 \mathrm{rpm}$ (Figure 3A). Moreover, a noteworthy difference in total lipid contents was noticed at an agitation speed of $220 \mathrm{rpm}$ (Figure 3B). Overall, the biomass and lipid productivities increased from 150 to $220 \mathrm{rpm}$ and then decreased from 220 to $300 \mathrm{rpm}$ (Figure 3C). It has been previously reported that cells grow and multiply more rapidly to the optimum level in the presence of a high oxygen compared with a low oxygen supply, ultimately enhancing the biomass and lipid productivities [39,40]. The specific growth rate demonstrated an increment from 150 to $220 \mathrm{rpm}$ (i.e., $2.1 \mathrm{~d}^{-1}$ to $3.5 \mathrm{~d}^{-1}$ ). Conversely, increases in agitation speed above $220 \mathrm{rpm}$ negatively affected the growth rate to $1.55 \mathrm{~d}^{-1}$. The $M$. circinelloides strains were susceptible to a high agitation speed, and the overall growth rate declined above $300 \mathrm{rpm}$ [41].

\subsection{Effect of Carbon Sources on Fungal Biomass and Lipid Accumulation}

Among the essential nutrients, carbon source plays a promising role in the fermentation process because carbon sources are directly correlated with the fungal biomass and cellular metabolites. To evaluate an appropriate carbon source for optimum fungal cell growth, total lipid productivity, and MCFA production, three different carbon sources were employed as additional carbon sources along with modified $\mathrm{K}$ and $\mathrm{R}$ medium. A previous investigation has shown that coconut oil, palm oil, and some other vegetable oils (i.e., mostly consist of lauric acid, myristic acid, and palmitic acid) containing culture medium show positive effects on fungal biomass and lipid accumulation [42]. Thus, to elucidate the effects of the aforementioned oils on MCFAs, we cultured the engineered strain M65-TE-04 in modified K and R medium together with coconut oil (3\%), palm oil (3\%), glycerol (3\%), or sole glucose (for the control experiments). We chose these concentrations based on some of our preliminary work (data not shown), as well as our previous investigation using 3\% diverse oils [43]. The cell dry weight (CDW) and TFA contents for strain M65-TE-04 were shown in Figure 4A,B. The aforementioned fungal strains showed a maximum CDW with coconut oil mixed medium, i.e., $17.0 \mathrm{~g} / \mathrm{L}$ at $72 \mathrm{~h}$ of the cultivation period. The CDW for palm oil mixed medium and medium containing glycerol as a supplement were $13.0 \mathrm{~g} / \mathrm{L}$ and $10.0 \mathrm{~g} / \mathrm{L}$, respectively, which is appreciably higher in comparison to fungal cell cultured in only glucose-containing medium $(9.0 \mathrm{~g} / \mathrm{L})$ (Figure $4 \mathrm{~A})$. The TFA contents (\% CDW) were found to be $9.5 \%$ higher when the fungal strain M65-TE-04 was cultured in coconut oil mixed medium in comparison to control (Figure 4B). Interestingly, the highest CDW was determined for strain M65-TE-04 grown in coconut oil mixed medium over $72 \mathrm{~h}$. However, the highest TFA content in the aforementioned strain was obtained when the cells were grown in coconut oil. 

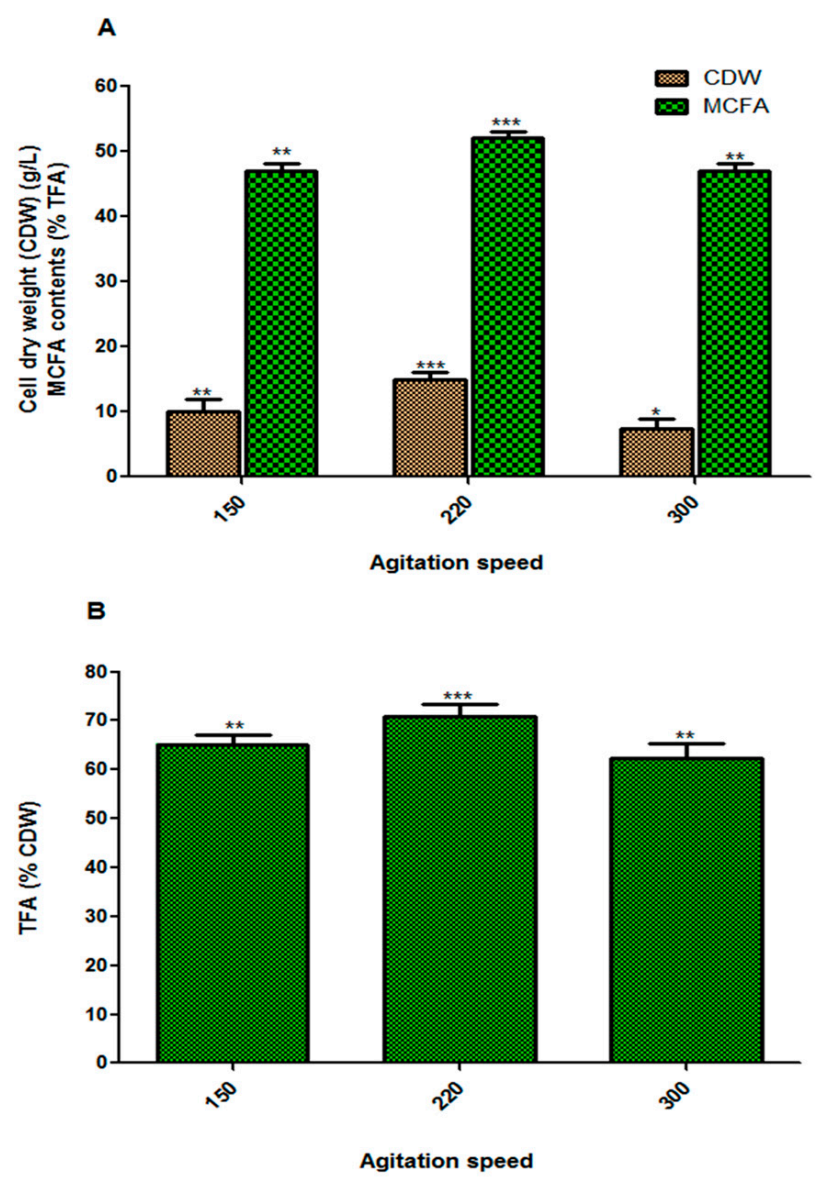

C

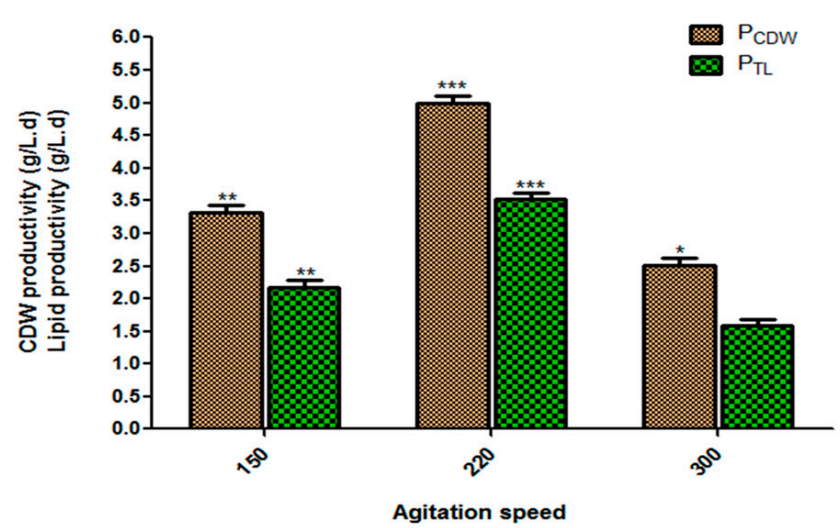

Figure 3. (A-C) Effect of agitation speed on (A) cell dry weight (CDW, g/L) and MCFA content (\% TLC), (B) fungal TFA (\% CDW), (C) biomass productivity $\left(\mathrm{P}_{\mathrm{CDW}}, \mathrm{g} / \mathrm{L} \cdot \mathrm{d}\right)$, and lipid productivity $\left(\mathrm{P}_{\mathrm{TL}}, \mathrm{g} / \mathrm{L} \cdot \mathrm{d}\right)$ of the $M$. circinelloides strain (i.e., M65-TE-04) after $72 \mathrm{~h}$ ( 3 days) of cultivation. Values are the mean of three independent experiments. Error bars show the standard error of the mean. Asterisks indicate that the differences $\left({ }^{*} p<0.05 ;{ }^{* *} p<0.01{ }^{* * *} p<0.001\right)$ between the means of different treatments are statistically significant. 

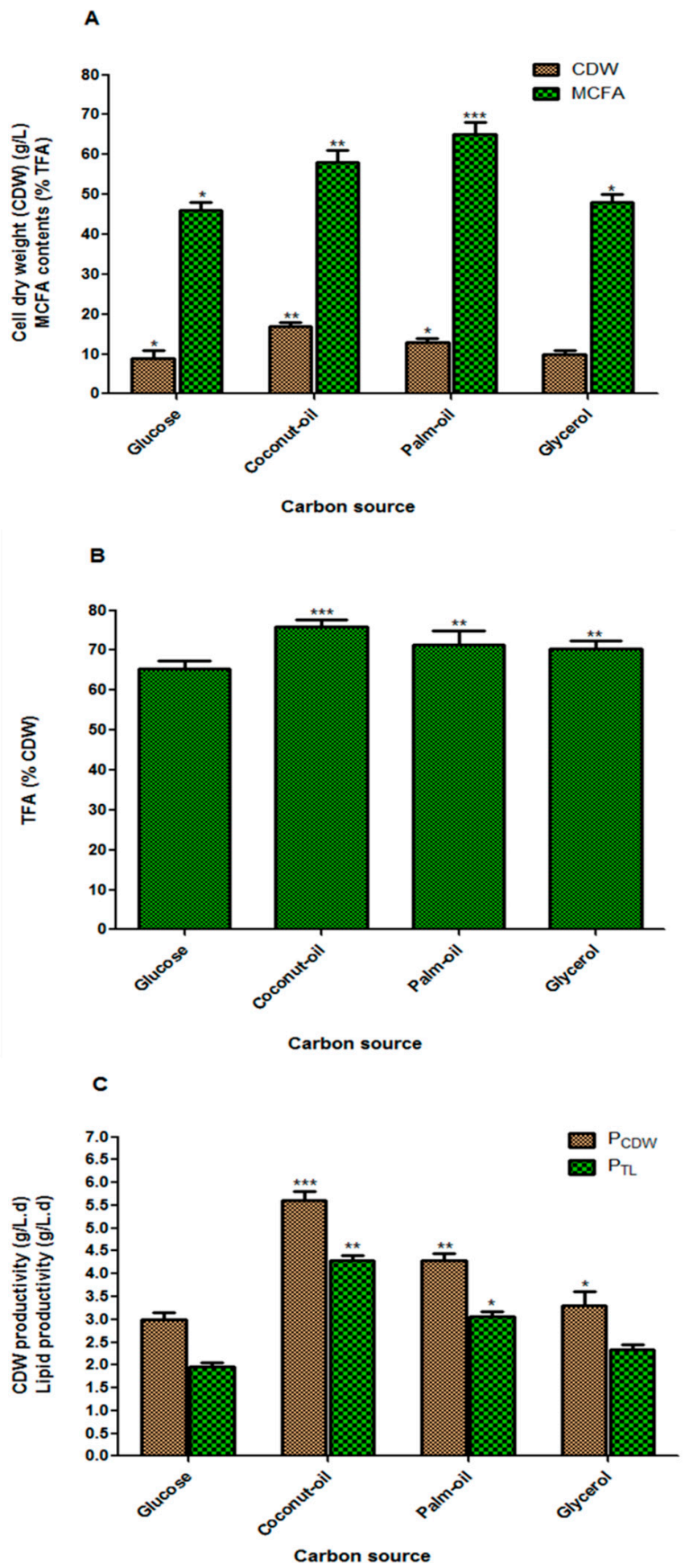

Figure 4. (A-C) Effect of different carbon sources on (A) cell dry weight (CDW, g/L) and MCFA content (\% TLC), (B) fungal TFA (\% CDW), (C) biomass productivity ( $\left.\mathrm{P}_{\mathrm{CDW}}, \mathrm{g} / \mathrm{L} \cdot \mathrm{d}\right)$, and lipid productivity $\left(\mathrm{P}_{\mathrm{TL}}, \mathrm{g} / \mathrm{L} \cdot \mathrm{d}\right)$ of the $M$. circinelloides strain (i.e., M65-TE-04) after $72 \mathrm{~h}$ (3 days) of cultivation. Values are the mean of three independent experiments. Error bars show the standard error of the mean. Asterisks indicate that the differences $\left({ }^{*} p<0.05 ;{ }^{* *} p<0.01 ;{ }^{* * *} p<0.001\right)$ between the means of different treatments are statistically significant.

The majority of the fatty acids in the M. circinelloides strain were palmitic acid, stearic acid, oleic acid, linoleic acid, and $\gamma$-linolenicacid. We observed a noteworthy difference in the fatty acid profile 
when strain M65-TE-04 was cultured in diverse glucose oil mixed medium. The fatty acid profile of M. circinelloides strain M65-TE-04 was directly associated with the fatty acid compositions of the glucose oil medium (Figure 5). The highest MCFA contents (i.e., 65\% CDW) were obtained when the fungal cells were grown in medium containing palm oil as a supplement (Figure 4A). In contrast, significant outcomes related to TFA contents were obtained when the fungal strain was grown in coconut oil mixed medium (Figure 4B). The biomass and lipid productivities $(p>0.05)$ for culture media containing different carbon sources are shown in Figure 4C.

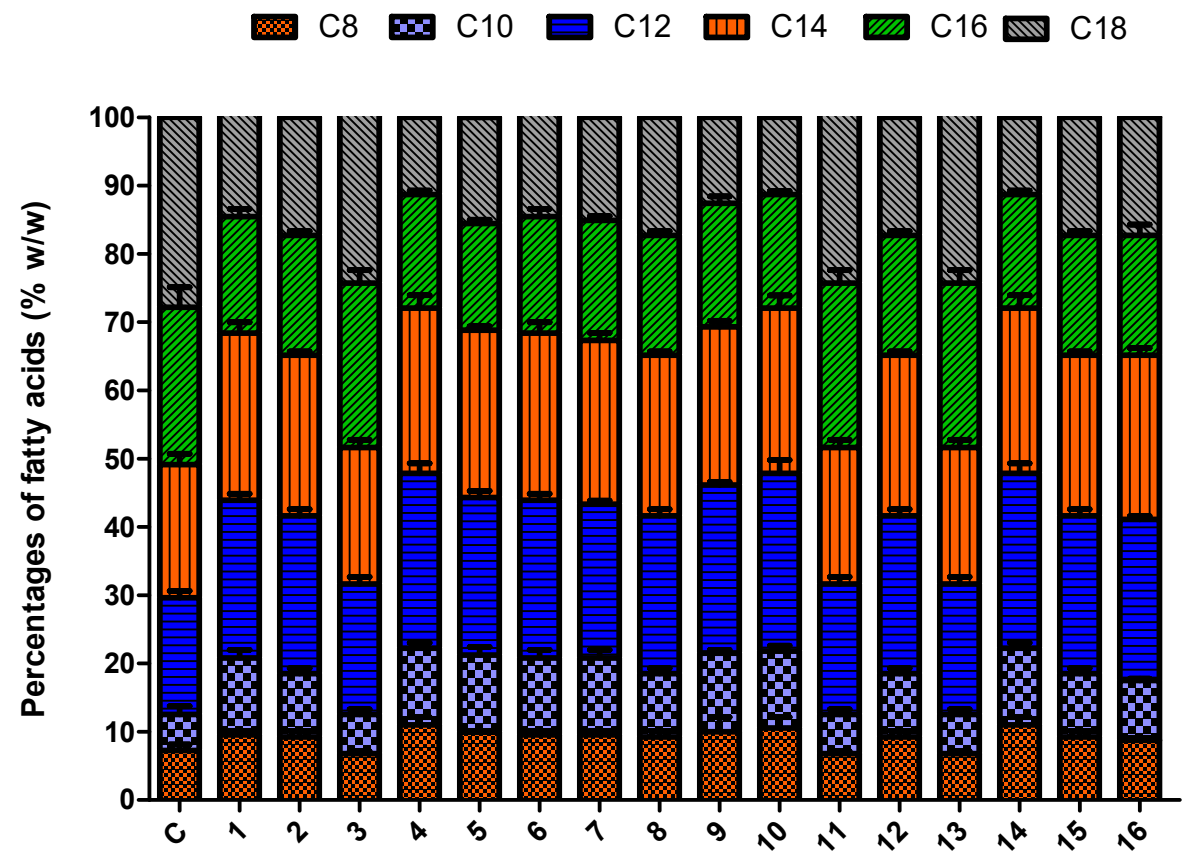

Assay

Figure 5. Fatty acid profile (\% of TFA) of the M. circinelloides strain (i.e., M65-TE-04) in the presence of differences in $\mathrm{pH}$, agitation speed, temperature, and carbon sources based on the orthogonal matrix design (OMD). The samples were harvested after $72 \mathrm{~h}$ ( 3 days) of cultivation. Values are the mean of three independent experiments. Error bars show the standard error of the mean.

Our results are consistent with previous studies showing that fungal cells produce more fungal biomass and total lipids when grown in medium-chain-containing oils [42-44]. Based on our results, the highest biomass and lipid productivities were achieved with coconut oil mixed medium $(\mathrm{g} / \mathrm{L} \cdot \mathrm{d})$, while the maximum MCFA contents in terms of the percentage of CDW were obtained with palm oil mixed medium (Figure 4C).

Taken together, we acquired diverse results among all individual variables for the culture growth conditions. Likewise, the highest biomass was obtained when coconut oil mixed medium was used as a carbon source under normal culture conditions; additionally, the highest fatty acid contents ( $\%$ $\mathrm{CDW})$ were achieved at $26^{\circ} \mathrm{C}$, the highest MCFA contents $(\% \mathrm{CDW})$ with palm oil mixed medium, and the maximum overall lipid productivity $(8.6 \mathrm{~g} / \mathrm{L} \cdot \mathrm{d})$ with coconut oil supplementation. Since we obtained diverse outcomes under the different culture conditions, synergetic insights into the individual culture conditions are needed to evaluate the different combinations based on an orthogonal matrix design (OMD).

\subsection{Synergistic Effect of the Culture Conditions on Fungal Biomass and Lipid Accumulation}

To investigate cell growth and lipid accumulation of the strain M. circinelloides M65-TE-04, the fungal cells were cultured under different conditions. The coded values of individual variables by 
the orthogonal matrix design (OMD) are provided in Table 1. All the experiments were carried out in a 1-L baffled shake flask with $250 \mathrm{~mL}$ modified $\mathrm{K}$ and $\mathrm{R}$ medium containing glucose or other carbon sources (see Section 2.1 for details). The responses for the four independent variables (i.e., temperature, agitation, $\mathrm{pH}$, and carbon sources) obtained based on the orthogonal matrix design (OMD) (SPSS 19) were provided in Table 2.

Table 2. Orthogonal matrix design (OMD) for the combination of different culture conditions (coded values) and their responses in biomass contents (CDW, g/L), lipid contents (TFA,\% CDW), MCFA contents (MCFA,\% TFA), lipid productivity $\left(\mathrm{P}_{\mathrm{TL}}, \mathrm{mg} / \mathrm{L} \cdot \mathrm{d}\right)$, and MCFA productivity $\left(\mathrm{P}_{\mathrm{MCFA}}, \mathrm{mg} / \mathrm{L} \cdot \mathrm{d}\right)$ of M. circinelloides strain (i.e., M65-TE-04) after $72 \mathrm{~h}$ (3 days) of cultivation period. Values were the mean of three independent experiments.

\begin{tabular}{|c|c|c|c|c|c|c|c|c|c|c|c|c|}
\hline Assay & $\mathrm{pH}$ & Agitation speed & Temperature & Carbon-Source & CDW & TFA & MCFA & $\mathrm{C}_{\mathrm{TL}}$ & $\mathrm{C}_{\text {MCFA }}$ & $\mathbf{P}_{\mathrm{TL}}$ & $\mathbf{P}_{\text {MCFA }}$ & Yield \\
\hline 1 & 1 & 1 & 1 & 1 & 6.4 & 45.5 & 44.72 & 2.9 & 1.3 & 967 & 435 & 0.016 \\
\hline 2 & 3 & 3 & 1 & 3 & 3.3 & 55.45 & 48.25 & 1.8 & 0.86 & 600 & 286 & 0.010 \\
\hline 3 & 1 & 1 & 1 & 4 & 4.3 & 32.2 & 32.48 & 1.3 & 0.42 & 434 & 140 & 0.005 \\
\hline 4 & 2 & 2 & 1 & 2 & 10.7 & 69.2 & 55.25 & 7.4 & 4.01 & 2467 & 1337 & 0.051 \\
\hline 5 & 2 & 1 & 3 & 1 & 8.2 & 56.7 & 46.45 & 4.6 & 2.1 & 1534 & 700 & 0.026 \\
\hline 6 & 1 & 3 & 2 & 1 & 4.5 & 26.7 & 39.25 & 1.7 & 0.66 & 567 & 220 & 0.008 \\
\hline 7 & 3 & 2 & 4 & 1 & 7.8 & 18.2 & 52.3 & 1.4 & 0.73 & 467 & 244 & 0.009 \\
\hline 8 & 1 & 1 & 4 & 3 & 5.4 & 13.5 & 35.23 & 0.72 & 0.25 & 240 & 84 & 0.003 \\
\hline 9 & 1 & 1 & 4 & 2 & 4.5 & 16.9 & 45.26 & 0.76 & 0.34 & 254 & 114 & 0.004 \\
\hline 10 & 1 & 3 & 3 & 2 & 6.5 & 22.5 & 40.29 & 1.4 & 1.61 & 467 & 538 & 0.020 \\
\hline 11 & 2 & 3 & 4 & 4 & 9.7 & 40.3 & 42.49 & 3.9 & 1.65 & 1300 & 550 & 0.020 \\
\hline 12 & 2 & 1 & 2 & 3 & 16.3 & 67.1 & 49.47 & 10.1 & 5.01 & 3368 & 1670 & 0.062 \\
\hline 13 & 3 & 1 & 3 & 4 & 8.8 & 30.45 & 42.29 & 2.6 & 1.1 & 867 & 367 & 0.013 \\
\hline 14 & 3 & 1 & 2 & 2 & 11.5 & 38.22 & 39.21 & 4.39 & 1.7 & 1464 & 569 & 0.021 \\
\hline 15 & 1 & 2 & 3 & 3 & 3.6 & 36.2 & 48.45 & 1.3 & 0.62 & 434 & 207 & 0.007 \\
\hline 16 & 2 & 3 & 2 & 3 & 19.4 & 74.1 & 54.2 & 14.3 & 4.71 & 4767 & 2570 & 0.058 \\
\hline
\end{tabular}

$\mathrm{C}_{\mathrm{TL}} ;$ lipid content $(\mathrm{g} / \mathrm{L}) ; \mathrm{C}_{\mathrm{MCFA}}:$ MCFA content $(\mathrm{g} / \mathrm{L}) ; \mathrm{P}_{\mathrm{TL}}:$ lipid productivity $(\mathrm{mg} / \mathrm{L} \cdot \mathrm{d}) ; \mathrm{P}_{\mathrm{MCFA}}:$ MCFA productivity $(\mathrm{mg} / \mathrm{L} \cdot \mathrm{d})$.

We observed an elevation in biomass in assays 12 and 16 and a slight elevation in assays 14 and 4, while the lipid contents (\% CDW) exceeded the maximum in assay 16 and significantly exceeded the maximum in assays 12 and 4. Assays 2 and 5 also showed higher lipid contents (\% CDW). Overall, assays 16,12, and 4 demonstrated the highest lipid $(\mathrm{g} / \mathrm{L})$ and MCFA contents $(\mathrm{g} / \mathrm{L})$, as well as lipid and MCFA productivities ( $\mathrm{mg} / \mathrm{L} \cdot \mathrm{d})$, as shown in Table 2 . Thus, from the above discussion and the results represented in Table 2, we concluded that assay 16 with specific cultivation conditions (i.e., temperature $26^{\circ} \mathrm{C}, \mathrm{pH} 6$, agitation speed $300 \mathrm{rpm}, 3 \%$ coconut oil mixed medium as the carbon source) provided the best outcome for M. circinelloides strain M65-TE-04among all 16 assays. This condition eventually provided the highest lipid (i.e., $4767 \mathrm{mg} / \mathrm{L} \cdot d$ ) and MCFA productivity (i.e., $2570 \mathrm{mg} / \mathrm{L} \cdot \mathrm{d}$ ) (Table 2). The higher contents of MCFA obtained in M. circinelloides (M65-TE-04) by using coconut oil. This is might be due to availability of MCFA in coconut oil, and therefore it shows that $M$. circinelloides should assimilate the MCFA from the coconut into their cells.

M. circinelloides naturally produces LCFAs, eventually making it less attractive for use as a precursor in the food, biochemical, and aviation industries. In our recent investigation, we genetically manipulated M. circinelloides strain M65, ultimately to obtain mutant strains with high MCFA-producing ability. Although we were successful, the resultant strains showed a very low biomass, which eventually affected the lipid and MCFA productivity [1]. Thus, the approach used in the present study, optimizing the cultivation conditions (i.e., assay 16$)$ to enhance the MCFA yield $(\mathrm{g} / \mathrm{L})$ and contents $(\% \mathrm{TFA})$ in M. circinelloides, fulfilled the primary objective of the current investigation. No studies have yet been conducted in this respect. The utilization of different agriculture by-products (i.e., copra cake, palm fruit cake) as supplementation for the culture medium, which would be environmentally friendly and cost effective, is our next possible objective. 


\section{Conclusions}

In the current investigation, we assessed whether the capability of the engineered strain of $M$. circinelloides (i.e., M65-TE-04) to generate MCFAs could be improved by choosing appropriate culture medium ingredients and culture conditions. We noticed significant increments (\%) in biomass, TFA, and MCFA contents (i.e., $112.25 \%, 139.93 \%$, and $70 \%$ respectively) by applying the combination of physical parameters: temperature $26^{\circ} \mathrm{C}, \mathrm{pH}$, agitation speed $300 \mathrm{rpm}$, and $3 \%$ coconut oil mixed medium as the carbon source. These results suggested that $M$. circinelloides strain M65-TE-04 could utilize a common lipid to overproduce MCFAs, thus revealing the extensive biotechnological significance of this fungus. The coconut oil mixed medium stimulated fungal cell growth and MCFA production more effectively than palm oil and glycerol. However, sufficient space remains to enhance MCFA production in M. circinelloides through the use of diverse strategies. Conclusively, this investigation could be used to further exploit industrial MCFA production using the engineered M. circinelloides strain.

Author Contributions: S.A.H. and Y.N. carried out the experiments. S.A.H. drafted the manuscript. A.H., W.Y., and K.M. assisted in GC analysis. Y.S. conceived the study, participated in the experimental design, and reviewed the final manuscript. All authors read and approved the final manuscript.

Funding: This work was supported by National Natural Science Foundation of China (31670064), TaiShan Industrial Experts Program (tscy 20160101), Chinese Government Scholarship Council (CSC), and starting grant from Shandong University of Technology.

Acknowledgments: We thank to Wu Yang for technical support. We are also indebted to Scarlett Geunes-Boyer and Alexis Garcia for critical reading and discussions.

Conflicts of Interest: The authors declare no competing interests.

\section{References}

1. Hussain, S.A.; Hameed, A.; Khan, M.A.K.; Zhang, Y.; Zhang, H.; Garre, V.; Song, Y. Engineering of Fatty Acid Synthases (FASs) to Boost the Production of Medium-Chain Fatty Acids (MCFAs) in Mucor circinelloides. Int. J. Mol. Sci. 2019, 20, 786. [CrossRef] [PubMed]

2. Sarria, S.; Kruyer, N.S.; Yahya, P.P. Microbial synthesis of medium-chain chemicals from renewable. Nat. Biotechnol. 2017, 35, 1158-1166. [CrossRef] [PubMed]

3. Nagao, K.; Yanagita, T. Medium-chain fatty acids: Functional lipids for the prevention and treatment of the metabolic syndrome. Pharm. Res. 2010, 61, 208-212. [CrossRef]

4. Torella, J.P.; Ford, T.J.; Kim, S.N.; Chen, A.M.; Way, J.C.; Silver, P.A. Tailored fatty acid synthesis via dynamic control of fatty acid elongation. Proc. Nat. Acad. Sci. USA. 2013, 110, 11290-11295. [CrossRef] [PubMed]

5. Leber, C.; Da-Silva, N.A. Engineering of Saccharomyces cerevisiae for the synthesis of short chain fatty acids. Biotechnol. Bioeng. 2014, 111, 347-358. [CrossRef] [PubMed]

6. Xu, P.; Qiao, K.; Ahn, W.S. Stephanopoulos, G. Engineering Yarrowia lipolytica as a platform for synthesis of drop-in transportation fuels and oleochemicals. Proc. Natl. Acad. Sci. USA. 2016, 113, 10848-10853. [CrossRef]

7. Zhu, Z.; Zhou, Y.J.; Krivoruchko, A.; Grininger, M.; Zhao, Z.K.; Nielsen, J. Expanding the product portfolio of fungal type I fatty acid synthases. Nat. Chem. Biol. 2017, 13, 360-362. [CrossRef] [PubMed]

8. Liu, X.; Hicks, W.M.; Silver, P.A.; Way, J.C. Engineering acyl carrier protein to enhance production of shortened fatty acids. Biotechnol. Biofuel 2016, 9, 24. [CrossRef] [PubMed]

9. Gajewski, J.; Pavlovic, R.; Fischer, M.; Boles, E.; Grininger, M. Engineering fungal de novo fatty acid synthesis for short chain fatty acid production. Nat. Commun. 2017, 8, 14650. [CrossRef]

10. Liu, H.; Cheng, T.; Xian, M.; Cao, Y.; Fang, F.; Zou, H. Fatty acid from the renewable sources: A promising feedstock for the production of biofuels and biobased chemicals. Biotechnol. Adv. 2014, 32, 382-389. [CrossRef] [PubMed]

11. Lynd, L.R.; Zyl, V.W.H.; Mc Bride, J.E.; Laser, M. Consolidated bioprocessing of cellulosic biomass: An update. Curr. Opin. Biotechnol. 2005, 16, 577-583. [CrossRef] [PubMed]

12. Runguphan, W.; Keasling, J.D. Metabolic engineering of Saccharomyces cerevisiae for production of fatty acid-derived biofuels and chemicals. Metab. Eng. 2014, 21, 103-113. [CrossRef] [PubMed] 
13. Lian, J.; Zhao, H. Reversal of the $\beta$-oxidation cycle in Saccharomyces cerevisiae for production of fuels and chemicals. ACS Synth. Biol. 2015, 4, 332-341. [CrossRef]

14. Dellomonaco, C.; Clomburg, J.M.; Miller, E.N.; Gonzalez, R. Engineered reversal of the $\beta$-oxidation cycle for the synthesis of fuels and chemicals. Nature 2011, 476, 355-3559. [CrossRef] [PubMed]

15. Kim, S.; Clomburg, J.M.; Gonzalez, R. Synthesis of medium-chain length (C6-C10) fuels and chemicals via $\beta$-oxidation reversal in Escherichia coli. J. Ind. Microbiol. Biotechnol. 2015, 42, 465-475. [CrossRef] [PubMed]

16. Grisewood, M.J.; Grisewood, M.J.; Hernandez Lozada, N.J.; Thoden, J.B.; Gifford, N.P.; Mendez-Perez, D.; Schoenberger, H.A.; Allan, M.F.; Floy, M.E.; Lai, R.Y.; Holden, H.M.; et al. Computational redesign of acyl-ACP thioesterase with improved selectivity toward medium-chain-length fatty acids. ACS Catal. 2017, 7, 3837-3849. [CrossRef] [PubMed]

17. Ageitos, J.M.; Vallejo, J.A.; Veiga-Crespo, P.; Villa, T.G. Oily yeasts as oleaginous cell factories. Appl. Microbiol. Biotechnol. 2011, 90, 1219-1227. [CrossRef]

18. Beopoulos, A.; Chardo, T.; Nicaud, J.M. Yarrowia lipolytica: A model and a tool to understand the mechanisms implicated in lipid accumulation. Biochimie 2009, 91, 692-696. [CrossRef]

19. Papanikolaou, S.; Aggelis, G. Lipids of oleaginous yeasts. Part II: Technology and potential applications. Euro. J. Lipid Sci. Technol. 2011, 113, 1052-1073. [CrossRef]

20. Huan, L.; Zhao, L.; Zan, X.; Song, Y.; Ratledge, C. Boosting fatty acid synthesis in Rhodococcus opacus PD630 by overexpression of autologous thioesterases. Biotechnol. Lett. 2016, 38, 999-1008. [CrossRef]

21. Rigouin, C.; Croux, C.; Borsenberger, V.; Khaled, M.B.; Chardot, T.; Marty, A.; Bordes, F. Increasing medium chain fatty acids production in Yarrowia lipolytica by metabolic engineering. Microb. Cell Fact. 2018, 17, 142. [CrossRef] [PubMed]

22. Chen, L.; Zhang, J.; Chen, W.N. Engineering the Saccharomyces cerevisiae $\beta$-Oxidation Pathway to Increase Medium Chain Fatty Acid Production as Potential Biofuel. PLoS ONE 2014, 9, e84853. [CrossRef] [PubMed]

23. Aggelis, G. Two alternative pathways for substrate assimilation by Mucor circinelloides. Folia Microbiol. 1996, 41, 254-256. [CrossRef]

24. Chen, H.C.; Liu, T.M. Inoculum effects on the production of $\gamma$-linolenic acid by the shake culture of Cunninghamella echinulata CCRC 31840. Enz. Microb. Technol. 1997, 21, 137-142. [CrossRef]

25. Conti, E.; Stredansky, M.; Stredanska, S.; Zanetti, F. $\gamma$-Linolenic acid production by solid-state fermentation of Mucorales strains on cereals. Bioresour. Technol. 2001, 76, 283-286. [CrossRef]

26. Emelyanova, E.V. Lipid and $\gamma$-linolenic acid production by Mucor inaquisporus. Proc. Biochem. 1997, 32, 173-177. [CrossRef]

27. Roux, M.P.; Kock, J.L.F.; Du Preez, J.C.; Botha, A. The influence of dissolved oxygen tension on the production of cocoa butter equivalents and gamma-linolenic acid by Mucor circinelloides. System. Appl. Microbiol. 1995, 18, 329-334. [CrossRef]

28. Khan, M.A.K.; Yang, J.; Hussain, S.A.; Zhang, H.; Garre, V.; Song, Y. Genetic modification of Mucor circinelloides to construct stearidonic acid producing cell factory. Int. J. Mol. Sci. 2019, 20, 1683. [CrossRef]

29. Stredansky, M.; Conti, E.; Stredanska, S.; Zanetti, F. $\gamma$-linolenic acid production with Thamnidium elegans by solid state fermentation on apple pomace. Bioresour. Technol. 2000, 73, 41-45. [CrossRef]

30. Tauk-Tornisielo, S.M.; Vieira, J.M.; Carneiro, M.C.V.S.; Govone, J.S. Fatty acid production by four strains of Mucor hiemalis grown in plant oil and soluble carbohydrates. Afr. J. Biotechnol. 2007, 6, 1840-1847.

31. Torlanova, B.O.; Funtikova, N.S.; Konova, I.V.; Babanova, N.K. Synthesis of the lipid complex containing gamma-linolenic acid and carotenoids by a mucorous fungus under various cultivation conditions. Microbiology 1995, 64, 492-496.

32. Vaughn, D.M.; Reinhart, G.A. Influence dietary fatty acid ratios on tissue eicosanoid production and blood coagulation parameters in dog. In Recent Advances in Canine and Feline Nutritional Research-Ians International Nutrition Symposium; Orange Frazer Press: Wilmington, OH, USA, 1996; pp. 243-255.

33. Khan, M.A.K.; Yang, J.; Luan, X.; Hussain, S.A.; Zhang, H.; Liang, L.; Garre, V.; Song, Y. Construction of DGLA producing cell factory by genetic modification of Mucor circinelloides. Microb. Cell Fact. 2019, 18, 64. [CrossRef] [PubMed]

34. Xia, C.; Zhang, J.; Zhang, W.; Hu, B. A new cultivation method for microbial oil production: cell pelletization and lipid accumulation by Mucor circinelloides. Biotechnol. Biofuels 2011, 4, 15. [CrossRef]

35. Morin-Sardin, S.K.; Coroller, L.; Jany, J.L.; Coton, E. Effect of temperature, pH, and water activity on Mucor spp. growth on synthetic medium, cheese analog and cheese. Food Microbiol. 2016, 56, 69-79. [PubMed] 
36. Suutari, M. Effect of growth temperature on lipid fatty acids of four fungi (Aspergillus niger, Nurosporacrassa, Penicillium chrysogenum and Trichoderma reesei. Arc. Micro. 1995, 164, 212-216. [CrossRef]

37. Vylkova, S. Environmental $\mathrm{pH}$ modulation by pathogenic fungi as a strategy to conquer the host. PLoS Pathog. 2017, 13, e1006149. [CrossRef] [PubMed]

38. Trzaska, W.J.; Correia, J.N.; Villegas, M.T.; May, R.C.; Voelz, K. pH Manipulation as a Novel Strategy for Treating Mucormycosis. Anti Age. Chemother. 2015, 59, 6968-6974. [CrossRef] [PubMed]

39. Azmi, W.; Thakur, M.; Javed, A.; Thakur, N. Interactive Effect of Agitation Speed and Aeration Rate on Heat Stable $\beta$-carotene Production From Mucor azygosporus Using Deprotenized Waste Whey Filtrate in Stirred Tank Reactor. Curr. Biochem. Engin. 2015, 2, 65-72. [CrossRef]

40. Ibrahim, D.; Weloosamy, H.; Lim, S.H. Effect of agitation speed on the morphology of Aspergillus niger HFD5A-1 hyphae and its pectinase production in submerged fermentation. World J. Biol. Chem. 2015, 6, 265-271. [CrossRef]

41. Saad, N.; Abdeshahian, P.; Kalil, M.S.; Yusoff, W.M.W.; Hamid, A.A. Optimization of Aeration and Agitation Rate for Lipid and Gamma Linolenic Acid Productio by Cunningha mellabainieri 2A1 in Submerged Fermentation Using Response Surface Methodology. Sci. World J. 2014, 2014, 280146. [CrossRef]

42. Zan, X.; Tang, X.; Chu, L.; Song, Y. Characteristics of cell growth and lipid accumulation of high and low lipid-producing strains of Mucor circinelloides grown on different glucose-oil mixed media. Pro. Biochem. 2018, 72, 31-40. [CrossRef]

43. Tauk-Tornisielo, S.M.; Arasato, L.S.; de-Almeida, A.F.; Govone, J.S.; Malagutti, E.N. Lipid formation and $\gamma$-linolenic acid production by Mucor circinelloides and Rhizopus sp., grown on vegetable oil. Braz. J. Microbiol. 2009, 40, 342-345. [CrossRef] [PubMed]

44. Du Preez, J.C.; Immelman, M.; Kock, J.L.F.; Kilian, S.G. Production of $\gamma$-linolenic acid by Mucor circinelloides and Mucor rouxii with acetic acid as carbon substrate. Biotechnol. Lett. 1995, 17, 933-938. [CrossRef]

(C) 2019 by the authors. Licensee MDPI, Basel, Switzerland. This article is an open access article distributed under the terms and conditions of the Creative Commons Attribution (CC BY) license (http://creativecommons.org/licenses/by/4.0/). 